\title{
TRIPLE BAND-NOTCH UWB ANTENNA WITH SRRS AND CSRRS
}

\author{
Ritesh Kumar Saraswat ${ }^{1}$, Hemant Kumar $^{2}$, Chetan Prakash ${ }^{3}$ and Abdul Hakeem ${ }^{4}$
}

\begin{abstract}
A Proposal is made for a triple band notched (UWB) antenna loaded with SRRs and CSRR patch with micro-strip fed line, on FR for substract in trapezoidal shape. Notch bands are achieved around the WLAN (5.15-5.25 GHz), WiMAX (3.3-3.8GHz) and X-band (7.9-8.4-GHz) by etching one elliptic single complementary split-ring resonator (ESCSRR) from the radiating patch and, by placing two square single split-ring resonators(SSSRRs) of different dimensions near the feedline, respectively. Results are expressed experimentally over the UWB operation.

Index Terms-Elliptic single complementary split-ring resonator (ESCSRR), square single splitring resonators (SSSRRs), ultrawideband (UWB), triple notch band, WiMAX, WLAN.
\end{abstract}

\section{INTRODUCTION}

In 2002, The ultra-wideband (UWB) spectrum from 3.1 to 10.6 Ghz US Fedral Communications Commission (FCC), for commercial communication applications. The Wireless Personal Area Networks, remote sensing, imaging radar, among others along with high data communication rates and low power consumption are mostly used in The UWB communication systems. But this may face problems like electromagnetic interference (EMI) which is occurred due to the presence of narrowband communication systems like WiMAX, WLAN, or X-band satellite communication links. We can achieve the desired band rejection by inserting the external bandstop filters, but it can create some system complexities. So the designers follow the way of embedding parasitic strips or slots on radiating patch element or ground plane of different shapes and sizes to eliminate such problems. Also Reconfigurable multiple band notched UWB antennas have been proposed by using split-ring resonators and complementary split-ring resonators (CSRRs).

So we are here to discuss about the design of a simple low-cost micros trio-fed UWB antenna with the properties of triple band-notched. To eliminate the trapezoidal shape radiating patch to avoid the interference because of WLAN frequency $(5.150-5.250 \mathrm{Ghz})$ we use a elliptic single split-ring resonator (ESSRR). Also there is an elliptical shape has same area as that of a circle would have greater perimeter, provide lesser resonant frequency. It causes miniaturization of the band-reject elements. So The elliptic SSRRs are most suitable for this proposed antenna. So two square single split-ring resonators (SSSRSs) with different dimensions are placed near the junction of feedline and radiating element as parasitic elements, to reject WiMAX frequency $(3.3-3.8-\mathrm{GHz})$ and ITU-specified $\mathrm{X}$-band communication frequency (7.9-8.4-GHz).

\footnotetext{
${ }^{1}$ M.L.V. Govt.Textile \& Engineering College Bhilwara(Rajasthan)

${ }^{2}$ M.L.V. Govt.Textile \& Engineering College Bhilwara(Rajasthan)

${ }^{3}$ M.L.V. Govt.Textile \& Engineering College Bhilwara(Rajasthan)

${ }^{4}$ M.L.V. Govt.Textile \& Engineering College Bhilwara(Rajasthan)
} 
Following section is all about the proposed antenna methodology with the radiation characteristics with comparison of simulated and measured results of VSWR, gain and radiation patterns. Hence we can find conclusions.

\section{ANTENNA DESIGN METHODOLOGY}

The topology of the proposed triple band-notched UWB antenna is shown in Figure 1.

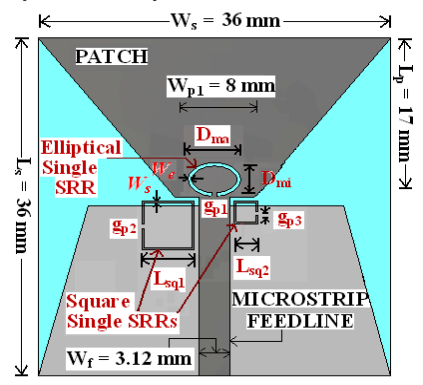

(a)

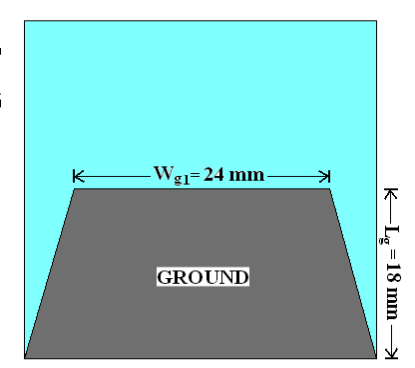

(b)

Figure 1 Configuration oftheproposedtriple band-notched UWB antenna. (a) Front view of structure, (b) back view of structure.

The radiating element is a trapezoidal shape patch

Dimensions:-

major arm length $\left(\mathrm{W}_{\mathrm{S}}\right)=36 \mathrm{~mm}$,

minor arm length $\left(\mathrm{W}_{\mathrm{P} 1}\right)=8 \mathrm{~mm}$

height $\left(\mathrm{L}_{\mathrm{P}}\right)=17 \mathrm{~mm}$

The radiating patch is fed by a 50- microstrip line, he dimesnions are below

length $=19 \mathrm{~mm}$ and width $\mathrm{W}_{\mathrm{f}}=3.12 \mathrm{~mm}$

The shape of the ground plane is also trapezoidal, dimensions are below

major arm length $=36 \mathrm{~mm}$

minor arm length $\left(\mathrm{W}_{\mathrm{g} 1}\right)=24 \mathrm{~mm}$

height $\left(\mathrm{L}_{\mathrm{g}}\right)=18 \mathrm{~mm}$

The proposed antenna is constructed on a $1.6 \mathrm{~mm}$ thick FR4 substrate with dielectric constant 4.3 and loss tangent 0.02 . The size of the substrate is $36 \times 36 \mathrm{~mm}^{2}$.

As per the design evolution of the proposed antenna from Figure 2, firstly using the finite integration technique (FIT)- based commercial electromagnetic simulator CST the simulation is introduced at the reference UWB antenna.
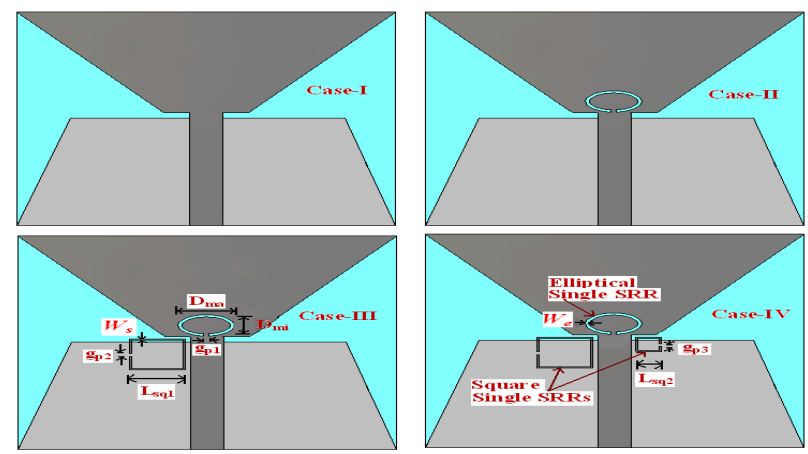

Figure 2 Design evolution of the proposed triple band-notched UWB monopole antenna. 
At the optimised values of antenna dimensions we get an impedance bandwidth (VSWR < 2) of $129.6 \%$ as shown in Figure 3, it covers the UWB frequency range specified by FCC. Plus the proposed antenna dimensions are quite compact of the electrical dimensions at lower frequency pf patch. It achieves notch-band around the WLAN (Case-II). In the case- III the ESSRR and one SSSRR it achieves double notch-bands around WLAN and WiMAX, it achieves triple notch-bands around the WLAN, WiMAX as well as X brand.

To get the desired triple band-notched properties using one ESSRR and two square single SRRs of different dimensions on the reference UWB antenna as shown in the Figure -2 (CASE-IV). The head to toe analysis of the dimensions of the band notched elements ESSRR and SSSRRs is shown in Section A and B.

\section{A. Analysis of ESSRR Dimensions}

The design equations to obtain a band-notch at frequency $f_{\text {notch }}$ for an elliptic single split-ring resonator (ESSRR) of major axis length $\mathrm{D}_{\mathrm{ma}}$, minor axis length $\mathrm{D}_{\mathrm{mi}}$, and width $W_{e}$ [Figure 1(a)], is defined as

$$
\begin{aligned}
& \text { Sri }=\pi \operatorname{Keff}\left(\frac{1}{2} \mathrm{D} m i-W e\right)=\frac{\lambda g}{2}=\frac{\mathrm{c}}{2 \mathrm{fn} 1 \sqrt{\text { geff }}} \\
& \text { Keff }=3(1+\mathrm{kr})-\sqrt{(3+\mathrm{kr})(1+3 \mathrm{kr})} \\
& \text { geff }=0.5(\mathrm{er}+1)+\frac{0.5(\mathrm{er}-1)}{\sqrt{1+\frac{12 \hbar}{\mathrm{W} T}}}
\end{aligned}
$$

In equation (1), $\mathrm{S}_{\mathrm{re}} \mathrm{Is}$ the inner circumference of ESSRR. It is approximately equal to half of the guided wavelength $\left(\lambda_{\mathrm{g}}\right)$ at the desired notch frequency $\left(\mathrm{f}_{\mathrm{n} 1}\right)$. The factor $\mathrm{K}_{\mathrm{eff}}$ is derived by using the equation (2), which is used for the calculation of circumference of the ellipse and is related with the ellipticity $k_{\mathrm{r}}\left(=\mathrm{D}_{\mathrm{ma}} / \mathrm{D}_{\mathrm{mi}}\right)$ [10]. The effective dielectric constant $\left(\varepsilon_{\mathrm{eff}}\right)$ is obtained by using equation (3), here $\varepsilon_{\mathrm{r}}, \mathrm{W}_{\mathrm{f}}$, and $\mathrm{h}$ are the relative permittivity of substrate, width of the microstrip feed line and substrate heightrespectively [12]. The width of ESSRR slots $\left(W_{\mathrm{e}}\right)$ at $0.4 \mathrm{~mm}$ fixed in our proposed design. Therefore, by properly choosing the values of $\mathrm{D}_{\mathrm{mi}}$ and $k_{\mathrm{r}}$ from equation (1) and (2) we can set the notch frequency $\mathrm{f}_{\mathrm{n} 1}$. From equation (2), if the ellipticity $k_{\mathrm{r}}$ is specified, we obtain the value of factor $K_{\text {eff }}$ and solve for $D_{m i}$ by using (1). By using equation (1) and (2) at any specified value of $D_{m i}$ can obtain a simple quadratic equation for determine the value of $\mathrm{k}$ analytically.

\section{B. Analysis ofSquare SSRR Dimensions}

To gain the desired parameters of the square single SRR for a required notch frequencyf $\mathrm{f}_{\mathrm{n} 2}$ and $\mathrm{f}_{\mathrm{n} 3}$ ,the guidelines may come handy to evaluate this.:

$$
\begin{aligned}
& \operatorname{Srs} 1=4(\mathrm{Lsq} 1-W s)=\frac{\lambda g}{2}=\frac{\mathrm{c}}{2 \mathrm{fn} 2 \sqrt{\operatorname{seff}}} \\
& \operatorname{Srs} 2=4(\mathrm{Lsq} 2-W s)=\frac{\lambda g}{2}=\frac{\mathrm{c}}{2 \mathrm{fn} 3 \sqrt{\operatorname{seff}}}
\end{aligned}
$$

Here, in the square single split rings

$$
\text { inner perimeter }-\mathrm{S}_{\mathrm{r} 1} \text { and } \mathrm{S}_{\mathrm{rs} 2}
$$

these are function of ring length $\mathrm{L}_{\mathrm{sq} 1} \& \mathrm{~L}_{\mathrm{sq} 2}$ and strip width $W_{\mathrm{s}}$ respectively, as shown in Figure 2 (Case-III \& IV). For the square SSRRRs, the inner perimeters $S_{\mathrm{rs}}$ should be equal $t$ half of the guided wavelength $\left(\lambda_{\mathrm{g}}\right)$ at the respective frequency to resonate at $\mathrm{f}_{\mathrm{n}}$.

\section{Full Wave Simulation}




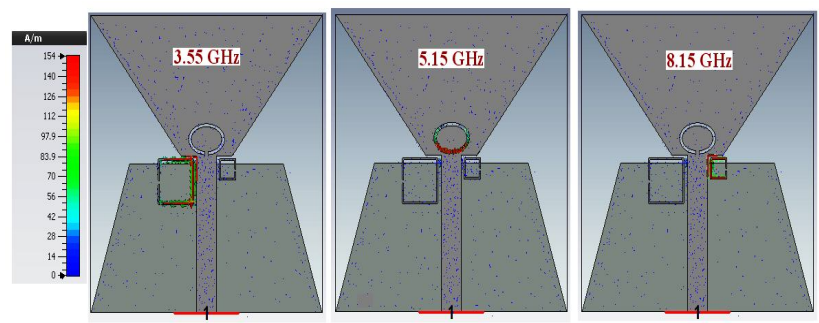

Figure 4Simulated results of surface current distribution for the proposed antenna at different central notch frequencies.

Figure 2 demonstrates the design evolution of proposed antenna in four different stages adopted in this paper. In Figure 3 variations of VSWR with frequency for these four design stages are represented. As shown in Figure 3, Case-I represents the reference UWB antenna. In case-II, one ESCSRR [shown in Figure 2] is incised out from radiating patch for obtaining a first band-notch at 5.17 GHz within the WLAN band $(5.150-5.250 \mathrm{GHz})$ from reference UWB antenna structure. We choose $D_{m i}=3.8 \mathrm{~mm}, g_{p 1}=W_{e}=0.4 \mathrm{~mm}$, and analytically obtain the required value of ellipticity $\mathrm{k}$ as 1.47 for case-II. We consider this value of ellipticity as an initial guess and carry out simulations with CST. It is noticed that the notch at $5.17 \mathrm{GHz}$ is obtained for $k=1.5$, while $D_{m i}, g_{p 1}$ and $W_{e}$ are kept fixed at the values used in the analytical prediction step.

As shown in fig-2, One square SSRR element of suitable dimensions is placed near the junction of the feedline and the radiating patch in case-III. To ensure effective coupling that result in band rejection around theWiMAX band the gap between the microstripfeedline and the SSRR is kept small. The gap is kept at $0.4 \mathrm{~mm}$ due to the limitations regarding printed circuit board (PCB) fabrication. In case-III, for obtaining the notch at $3.55 \mathrm{GHz}$ lying within the WiMAX band (3.3-3.8 GHz), we start with larger SSSRR parameter values $\mathrm{L}_{\mathrm{sq} 1}=5.9 \mathrm{~mm}$, $\mathrm{g}_{\mathrm{p} 2}$ $=0.4 \mathrm{~mm}$ and get $\mathrm{W}_{\mathrm{s}}=0.2 \mathrm{~mm}$ from the design guidelines in equation (4). The notch frequency $\mathrm{f}_{\mathrm{n} 2}$ at $3.5 \mathrm{GHz}$ is obtained at $\mathrm{L}_{\mathrm{sq} 1}=5.5 \mathrm{~mm}$ and $\mathrm{W}_{\mathrm{s}}=0.4 \mathrm{~mm}$ from CST simulations [17]. In Case-IV the final proposed design, an additional band notch at $8.01 \mathrm{GHz}$ within the X-band communication $(7.9-8.4 \mathrm{GHz})$ is obtained by using another smaller SSSRR having the following parameter values: $\mathrm{L}_{\mathrm{sq} 2}=2.78 \mathrm{~mm}, \mathrm{~g}_{\mathrm{p} 3}=0.4 \mathrm{~mm}$, and $\mathrm{W}_{\mathrm{s}}=$ $0.2 \mathrm{~mm}$ by using design equation (5). In CST simulation the third notch frequency $\mathrm{f}_{\mathrm{n} 3}$ at $8.01 \mathrm{GHz}$ is obtained at $\mathrm{L}_{\mathrm{sq} 2}=2.55 \mathrm{~mm}$ and $\mathrm{W}_{\mathrm{s}}=0.4 \mathrm{~mm}$

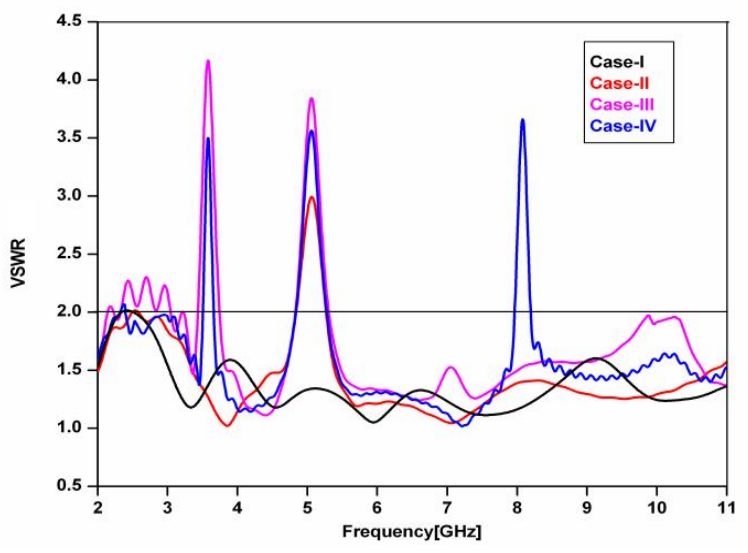

Figure 3Simulated VSWR for case I,II,III \& IV as mentioned in Figure 2.

As shown in Figure 4, in the locality of the larger SSSRR for $3.55 \mathrm{GHz}$, ESCSRR for $5.15 \mathrm{GHz}$ strong concentration of simulated surface current (represent by red color) is observed, and the smaller SSSRR for $8.15 \mathrm{GHz}$, clearly indicates the elements responsible for the band-notch characteristics in UWB range. 


\section{MEASUREMENT RESULTS AND DISCUSSION}

The derived UWB antenna is made on low cost FR4 substrate as shown in the figure. Here, Dilelectrc constant $=4.3$, loss tangent $=0.0$
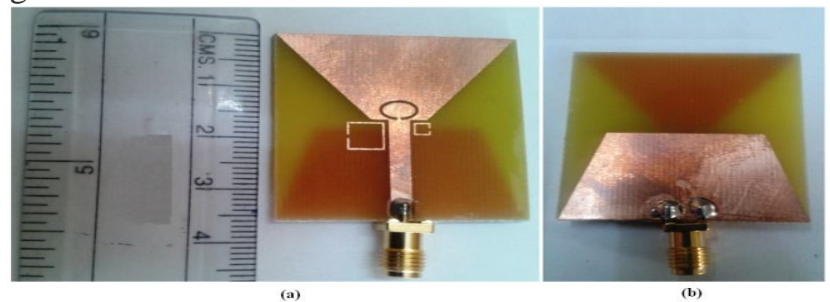

Figure 5 Image of the fabricated triple band-notched UWB proposed antenna: (a) top view; (b) bottom view.

Figure 6 is a difference between the simulated and measured VSWR of the derived antenna in UWB freq. range which is 3.1-10.6 Ghz. Now the VSWR of the antenna is more than 2 at 3 notch bands. It has a $n$ impedance bandwidth of $10.9 \%(3.39-3.78 \mathrm{GHz}), 9.4 \%(4.84-5.32 \mathrm{GHz}) \& 5.7 \%(7.89-8.35$ $\mathrm{GHz})$ under simulation and $7.8 \%(3.47-3.75 \mathrm{GHz}), 6.1 \%(4.95-5.26 \mathrm{GHz}) \& 4.8 \%(7.92-8.31 \mathrm{GHz}$ when measured.

These three notch-bands are the belonging to thefrequencies WiMAX, WLAN, and X-brand communication, respectively.

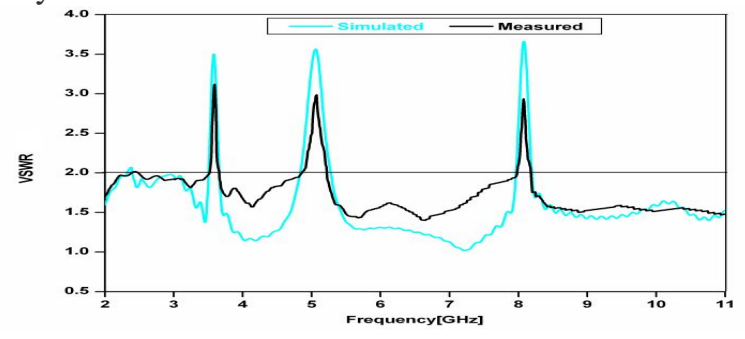

Figure 6 Simulated and measured VSWR of the proposed antenna.

Fig-7 shows the modelled and measured E-plane and H-plane radiation patterns for the proposed antenna at $4.5 \mathrm{GHz}, 5.5 \mathrm{GHz}, 7.0 \mathrm{GHz}$ and $10.0 \mathrm{GHz}$. The ploting of radiation patterns is of both coand cross-polarizations. It can be seen in the fig-7 that the E-plane radiation patterns are dipole-like radiation pattern whereas the character of the H-plane radiation patterns is omnidirectional . The achievement of E\& H-plane patterns is levels less than $-15 \mathrm{~dB}$ for all the frequency bands of interest. The E- and H- planes has a good agreement between the measured and simulated radiation patterns for co- and cross-polarizations to which the assembly misalignments caused difference.

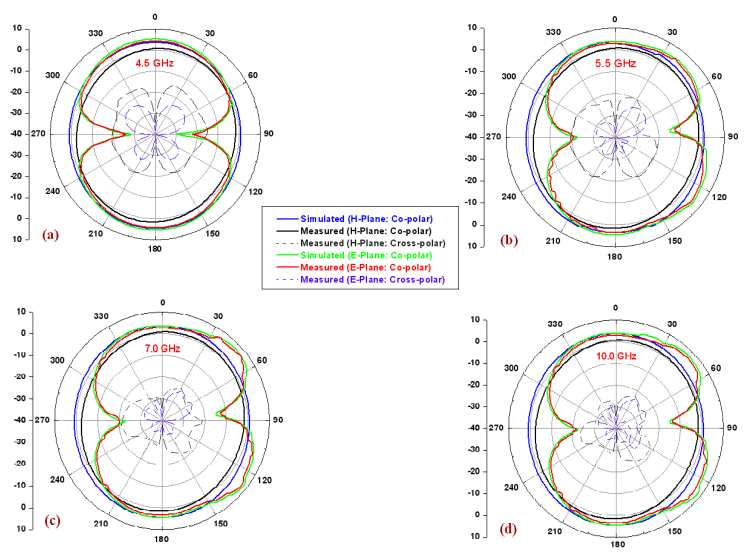

Figure 7. Simulated and measured E \& H-plane radiation patterns of the proposed antenna at; (a) 4.5 $\mathrm{GHz}$, (b) $5.5 \mathrm{GHz}$, (c) $7.0 \mathrm{GHz}$, and (d) $10.0 \mathrm{GHz}$, respectively. 
Most of the radiation patters are stable with the respected frequency. And the E plane pattern is slightly along the end fire directions at low frequencies $(<3 \mathrm{Ghz})$, Because of the increment cross polarization of the lower frequencies and unsuitability at higher frequencies.

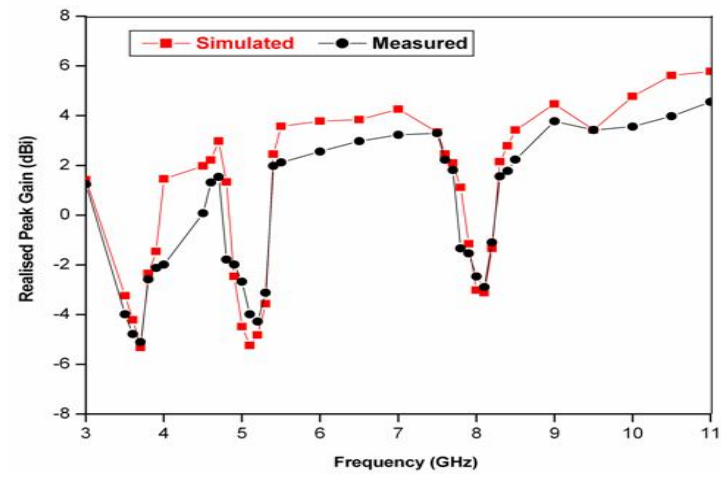

Figure 8.Simulated and measured realized gain of the proposed antenna.

The modelled and measured peak realized gain is reoresented by the fig- 8 of the proposed antenna over the frequency range 3-11 GHz (UWB band). It is noticed at three desired notch bands that there are Sharp dips in the value of realized far-field peak gain that gives a sign that the resonators (ESSRR and square SSRRs) provides excellent intrinsic filtering operation without the need of external circuitry. Gain is improved at higher frequency (above $6 \mathrm{GHz}$ ) besides these notch-bands with respect to the gain at lower frequency (below $4 \mathrm{GHz}$ ). $3.98 \mathrm{dBi}$ is the maximum measured realized peak gain and $2.55 \mathrm{dBi}$ is the average gain in UWB frequency range.

\section{CONCLUSION}

The proposed triple band-notched UWB antenna loaded with elliptic split ring and square split rings fed by a microstrip line is designed in the antenna structure, simulated and design for validating the experimental structure. The UWB Antenna's operating frequency range lies b/w 3.1-10.6 GHz, As well as three notch-bands at WiMAX having $3.3-3.8 \mathrm{GHz}$ freq., WLAN $(5.15-5.25 \mathrm{GHz})$, and Xband (7.9-8.4 GHz) Communication systems, respectively. The VSWR characteristics are observed of the antenna is more than 2 and gain is decreased significantly. The propsed antenna pattern is desined on low cost FR4 substrate, It can easily connect with wireless terminal devices. Obtained results are seen in good combination with the slmulated results.

\section{REFERENCES}

[1] Federal Communications Commission, Revision of part 15 of the commission's rules regarding ultra-wide band transmission systems, Technical Report, ET-Docket 98-153, FCC02-48, FCC, Washington, DC, April 2002.

[2] Q. X. Chu and Y. Y. Yang, "A compact ultrawideband antenna with 3.4/5.5 GHz dual bandnotched characteristics," IEEE Trans. AntennasPropag., vol. 56, no. 12, pp. 3637-3644, Dec. 2008.

[3] H. Zhang, R. Zhou, Z.Wu, H. Xin, and R. W. Ziolkowski, "Designs of ultra wideband (UWB) printed elliptical monopole antennas with slots," Microw. Opt. Technol. Lett., vol. 52, no. 2, pp. 466-471, Feb.2010.

[4] Ritesh K. Saraswat, and Mithilesh Kumar, "A Frequency Band Reconfigurable UWB Antenna for High Gain Applications," Progress In Electromagnetics Research B, Vol. 64, 29-45, 2015.

[5] Ritesh K. Saraswat, and Mithilesh Kumar, "Miniaturized Slotted Ground UWB Antenna Loaded with Metamaterial for WLAN and WiMAX Applications," Progress In Electromagnetics Research B, Vol. 65, 65-80, 2016.

[6] Y. Sung, "Triple band-notched UWB planar monopole antenna using a modified H-shaped resonator," IEEE Trans. Antennas Propag., vol. 61, no. 2, pp. 953-957, Feb. 2013.

[7] M. Ojaroudi, N. Ojaroudi, and N. Ghadimi, "Dual band-notched small monopole antenna with novel coupled inverted U-ring strip and novel fork-shaped slit for UWB applications," IEEE Antennas Wireless Propag. Lett., vol. 12, pp. 182-185, 2013. 
[8] M. Al-Husseini, J. Costantine, C. G. Christodoulou, S. E. Barbin, A. El-Hajj, and K. Y. Kabalan, "A reconfigurable frequency-notched UWB antenna with split-ring resonators," in Proc. Asia-Pacific Microw. Conf., Dec. 2012, pp. 618-621.

[9] C. C. Lin, P. Jin, and R. W. Ziolkowski, "Single, dual and tri-bandnotchedultrawideband (UWB) antennas using capacitively loaded loop (CLL) resonators," IEEE Trans. Antennas Propag., vol. 60, no. 1, pp. 102-109, Jan. 2012.

[10] P. Bourke, "Circumference of an ellipse," 2013 [Online]. Available: http://paulbourke.net/geometry/ellipsecirc/

[11] Computer Simulation Technology - CST (Microwave Studio MWS), Version-2014.

[12] D. M. Pozar, "Microwave Engineering”, 3rd ed. New York, NY, USA: Wiley, 2005. 